\title{
Erratum to: REM Sleep Behavior Disorder and REM Sleep Without Atonia as an Early Manifestation of Degenerative Neurological Disease
}

\author{
Stuart J. McCarter • Erik K. St. Louis • \\ Bradley F. Boeve
}

Published online: 10 March 2012

(C) Springer Science+Business Media, LLC 2012

\section{Erratum to: Curr Neurol Neurosci Rep \\ DOI 10.1007/s11910-012-0253-z}

McCarter SJ, St. Louis EK, Boeve BF: REM Sleep Behavior Disorder and REM Sleep Without Atonia as an Early Manifestation of Degenerative Neurological Disease. Curr Neurol Neurosci Rep 2012.

The abovementioned article was published online first on February 11, 2012 for the April 2012 issue of Current Neurology and Neuroscience Reports (volume 12, issue 2).

On page 184, the following italicized wording and reference citation were incorrect:

Due to the violent nature of dreams, injury often results in the form of bruises, head contusions, hair pulling, or fractures
$[2 \bullet \bullet, 6,9]$, and recently a single fatality caused by strangling of a patient's bed partner has been reported as resulting from $R B D$ [1].

The correct wording and reference should be the following:

Due to the violent nature of dreams, injury often results in the form of bruises, head contusions, hair pulling, or fractures $[2 \cdot \bullet, 6,9]$, and recently potentially lethal behaviors have been reported as resulting from RBD [97].

Reference 97: Schenck CH, Lee SA, Cramer Bornemann MA, Mahowald MW. Potentially lethal behaviors associated with rapid eye movement behavior disorder: review of the literature and forensic implications. J Forensic Sci 2009; 54 (6):1475-1484.

\footnotetext{
The online version of the original article can be found at http://dx.doi. org/10.1007/s11910-012-0253-Z.

S. J. McCarter · E. K. St. Louis · B. F. Boeve $(\varangle)$

Mayo Center for Sleep Medicine and Department of Neurology,

Mayo Clinic and Foundation,

200 First Street Southwest,

Rochester, MN 55905, USA

e-mail: bboeve@mayo.edu

\section{S. J. McCarter}

e-mail: mccarter.stuart@mayo.edu

E. K. St. Louis

e-mail: stlouis.erik@mayo.edu 